\title{
An Assessment of the Influence of Co-Inoculation with Endophytic Bacteria and Rhizobia, and the Influence of PRP SOL and PRP EBV Fertilisers on the Microbial Parameters of Soil and Nitrogenase Activity in Yellow Lupine (Lupinus luteus L.) Cultivation
}

\author{
Alicja Niewiadomska ${ }^{1 *}$, Hanna Sulewska ${ }^{2}$, Agnieszka Wolna-Maruwka ${ }^{1}$, \\ Karolina Ratajezak ${ }^{2}$, Katarzyna Gluchowska ${ }^{1}$, Zyta Waraczewska ${ }^{1}$, Anna Budka ${ }^{3}$ \\ 'Department of General and Environmental Microbiology, University of Life Sciences, Poznań, Poland \\ ${ }^{2}$ Department of Agronomy, University of Life Sciences, Poznań, Poland \\ ${ }^{3}$ Department of Mathematical and Statistical Methods, University of Life Sciences, Poznań, Poland
}

Received: 15 September 2017

Accepted: 22 October 2017

\begin{abstract}
The aim of the study was to determine the influence of PRP SOL and PRP EBV fertilisers and co-inoculation (simultaneous inoculation of plants with bacteria of the Rhizobium genus and endophytic Bacillus subtilis bacteria) on nitrogenase activity, the dynamics of growth of selected soil microorganisms, variation in soil biochemical properties, and soil fertility index in a yellow lupine plantation. There were 12 variants of the field experiment: 1) the control variant of uninoculated yellow lupine, 2) seeds inoculated with the Bacillus subtilis strain, 3) seeds inoculated with nitragin, 4) PRP SOL fertiliser, 5) PRP EBV fertiliser, 6) PRP SOL + PRP EBV, 7) PRP SOL fertiliser + Bacillus subtilis inoculation, 8) PRP SOL fertiliser + nitragin, 9) PRP SOL fertiliser + Bacillus subtilis + nitragin, 10) PRP EBV fertiliser + Bacillus subtilis, 11) PRP EBV fertiliser + Bacillus subtilis + nitragin, and 12) PRP SOL + PRP EBV + Bacillus subtilis + nitragin. Soil samples for microbiological and biochemical analyses were collected at 3 terms: during the emergence of plants, at the beginning of their florescence, and after harvesting. The count of selected groups of soil microorganisms (total bacterial count, moulds, Actinobacteria, copiotrophic and oligotrophic microorganisms) was measured with the serial dilution method developed by Koch. The analysis of soil enzymatic activity such as dehydrogenases and phosphatases in different variants was based on the colorimetric method, and catalase activity was measured with the manometric method. The two-year field experiment was conducted in 2014 and 2015. It showed that PRP SOL and PRP
\end{abstract}

*e-mail: alicja.niewiadomska@onet.eu 
EBV fertilisers and co-inoculation applied to the yellow lupine plantation stimulated nitrogenase activity, the dynamics of growth of selected groups of soil microorganisms, variation in biochemical activity, and soil fertility index.

Keywords: fertility index, number of microorganisms, Bacillus subtilis, enzymatic activity, nitragin

\section{Introduction}

At present we can see increasing interest in the search for agents that would optimise plants' uptake of nutrients from soil and simultaneously improve its chemical, biological, and physical properties [1]. These goals can be achieved by following the green biotechnology strategy and using microorganisms to increase the yield of crops. Bacteria of the Rhizobiaceae family, which fix molecular nitrogen in symbiosis with legumes, as well as plant growth promoting rhizobacteria (PGPR) are important for field-grown crops [2-3]. Contemporary agriculture needs to search for new agents aiding the development and yield of legumes. They should have high content of proteins and strong follow-up effect in the whole crop rotation.

PGPR microorganisms alter endogenous phytohormones stimulate the growth of roots (auxins, gibberellins, cytokinins) and reduce the concentration of ethylene, which inhibits this process and increases the weight of roots. Thus, they increase plants' surface of contact with soil. In consequence, there is better access and higher uptake of nutrients, which results in higher yield [4-5].

The availability of calcium, which has significant influence on the $\mathrm{pH}$ of the soil environment, is an important edaphic factor in the process of nitrogen fixation. When the calcium content in soil decreases, so does the capacity of rhizobia to colonise root hair. In consequence, the quantity of nitrogen fixed in nodules decreases, too. Calcium is also responsible for stabilizing the bacterial heterocyst capsule, which secures nitrogenase activity under oxidative stress [6]. The chemical composition of preparations applied to soil does not seem to be indifferent to nodule bacteria, endophytes, and plants. PRP SOL and PRP EBV fertilisers contain calcium, magnesium, sodium, and prefixes with which 48 trace elements (microelements) that are necessary for normal growth and development of plants enter soil [7]. Microelements - especially iron, manganese, zinc, copper, boron, molybdenum, etc. - have important functions in plants and microbial cells [8].

The aim of our study was to determine the influence of PRP SOL and PRP EBV fertilisers and co-inoculation (simultaneous inoculation of plants with bacteria of the Rhizobium genus and Bacillus subtilis endophyte) on nitrogenase activity, the dynamics of growth of selected soil microorganisms, variation in soil biochemical properties, and soil fertility index in a yellow lupine plantation.

\section{Materials and Methods}

Research on the influence of PRP SOL and PRP EBV fertilisers and co-inoculation of plants with endophytic and nodule bacteria in a yellow lupine plantation was conducted in 2014 and 2015 in Złotniki, in plots at the Gorzyń Experimental and Educational Station, Department of Agronomy, Poznań University of Life Sciences (GPS coordinates: N52029,193; E0160569). According to the FAO/WRB soil classification system [9], the soil in the experimental plots is classified as typical loessial soil, formed from sands from light loamy sand, deposited in a shallow layer on light clay (Haplic Luvisols) (Table 1).

During the experimental period the soil and climate were suitable for growing legumes in the plots. The weather conditions during the period of lupine growth were shown by means of Sielianinov's hydrothermal index [10] (Table 2). The index values showed variation in the weather during the experiment. The humidity was better for the crop in 2014 than in 2015, which was drier $(\mathrm{K}=0.9)$.

Interpretation of Sielianinov's hydrothermal index:

- $\mathrm{K}>1.5$ : excessive humidity for all plants

- $\mathrm{K}=1.0-1.5$ : adequate humidity

- $\mathrm{K}=0.5-1.0$ : insufficient humidity

- $\mathrm{K}<0.5$ : humidity below the required level for most plants (drought)

There were 4 replicates of the univariate experiment. There were 12 variants of the experiment: 1) the control variant of uninoculated yellow lupine, 2) seeds inoculated with the Bacillus subtilis strain, 3) seeds inoculated with nitragin, 4) PRP SOL fertiliser, 5) PRP EBV fertiliser, 6) PRP SOL + PRP EBV, 7) PRP SOL fertiliser + Bacillus subtilis inoculation, 8) PRP SOL fertiliser + nitragin, 9) PRP SOL fertiliser + Bacillus subtilis + nitragin, 10) PRP EBV fertiliser + Bacillus subtilis, 11) PRP EBV fertiliser + Bacillus subtilis + nitragin, and 12) PRP SOL + PRP $\mathrm{EBV}+$ Bacillus subtilis + nitragin.

Table 1. Characteristics of physical properties of the soil.

\begin{tabular}{|c|c|c|c|c|}
\hline $\begin{array}{c}\text { Layer of } \\
\text { soil }\end{array}$ & \multicolumn{4}{|c|}{ Granulometric composition } \\
\hline \multirow{3}{*}{ Level A } & Sand & Dust & Loam & $\begin{array}{c}\text { Granulometric } \\
\text { group }\end{array}$ \\
\cline { 2 - 5 } & $2-0.05$ & $0.05-0.002$ & & $\begin{array}{c}\text { wg. WRB } \\
2008\end{array}$ \\
\cline { 2 - 5 } & 78 & 18 & 4 & sl \\
\hline
\end{tabular}

sl - sandy loam 
Table. 2. Sielianinov hydrothermal coefficient (K) according to weather conditions from April to September at Experimental Station Złotniki in 2014-2015.

\begin{tabular}{|c|c|c|c|c|c|c|c|c|}
\hline \multirow{2}{*}{ Year } & \multicolumn{9}{|c|}{ Months } & \multirow{2}{*}{ Average } \\
\cline { 2 - 9 } & IV & V & VI & VII & VIII & IX & X & 1.25 \\
\hline 2014 & 1.81 & 2.25 & 0.89 & 0.70 & 1.68 & 1.01 & 0.40 & 0.92 \\
\hline 2015 & 0.90 & 1.10 & 0.57 & 0.91 & 1.24 & 0.84 & 0.93 & 1.16 \\
\hline Many years 51-15 & 1.14 & 1.72 & 1.16 & 0.79 & 1.39 & 1.28 & 1.16 \\
\hline
\end{tabular}

Before seeds were sown they were inoculated with nodule bacteria in the form of nitragin and Bacillus subtilis endophyte $\left(10^{8} \cdot \mathrm{ml}^{-1}\right.$ liquid culture). Before sowing in spring PRP SOL fertiliser was applied to soil at $300 \mathrm{~kg} / \mathrm{ha}$. The fertiliser is a granulate composed of $30 \% \mathrm{CaO}, 8 \% \mathrm{MgO}, 3.5 \% \mathrm{Na}$, and $3-5 \%$ prefixes, with which 48 trace elements (microelements) that are necessary for normal growth and development of plants are entered into soil. The fertiliser contains the following microelements: iron, manganese, zinc, copper, boron, and molybdenum.

PRP EBV is a fertiliser composed of potassium, magnesium, sodium, and copper. It was sprayed on yellow lupine 3 times at the following $\mathrm{BBCH}$ phases: $21 \mathrm{ha}^{-1}$ at BBCH 13-16 (3 do 6 leaves), $1.51 \mathrm{ha}^{-1}$ at $\mathrm{BBCH}$ 51-55 (closed flower buds), and $1.51 \mathrm{ha}^{-1}$ at $\mathrm{BBCH}$ 70-73 (emergence of pods).

The experiment was conducted to assess how the fertilisers and co-inoculation influenced nitrogenase activity and soil bioactivity.

\section{Assessing the Influence of PRP SOL and PRP EBV \\ Fertilisers and Co-Inoculation on Nitrogenase Activity (Diazotrophy)}

Five plants (on average) representing each experimental variant were selected to measure nitrogenase activity. The analyses were conducted at the beginning of the flowering period. Nitrogenase activity was measured with the acetylene method on a CHROM5 gas chromatograph [11]. The quantity of acetylene reduced to ethylene was measured and expressed as $\mathrm{nMC}_{2} \mathrm{H}_{4}$ plants $^{-1} \mathrm{~h}^{-1}$.

\section{Microbiological Analyses}

Samples of soil under the plants were collected for microbiological and biochemical analyses from a depth of 0-20 cm at the following 3 terms in 2014 and 2015: 1) at the plants' emergence (BBCH 5-10), 2) at the beginning of florescence (BBCH 51-59), and 3) after harvesting.

The count of selected groups of soil microorganisms (total bacterial count, moulds, Actinobacteria, copiotrophic, and oligotrophic microorganisms) was measured with the serial dilution method developed by Koch [12]. The measurements were repeated 5 times. The results were calculated per $1 \mathrm{~g}$ of dry mass of soil and expressed as colony-forming units (cfu). The groups of microorganisms were measured on selective mediums, using adequately diluted soil suspensions. The count of individual groups of microorganisms was measured in the following way:

- Total bacterial count - on a ready Merck standard agar after 3 days of incubation at $25^{\circ} \mathrm{C}$.

- Moulds - on a medium developed by Martin [13] after 5 days of incubation at $24^{\circ} \mathrm{C}$.

- Copiotrophs - on an NB medium [14] after 5 days of incubation at $25^{\circ} \mathrm{C}$.

- Oligotrophs - on a DNB medium [14] after 5 days of incubation at $25^{\circ} \mathrm{C}$.

- Actinobacteria - on a medium developed by Pochon after 5 days of culturing at $25^{\circ} \mathrm{C}$ [15].

\section{Biochemical Analyses of Soil}

The analysis of soil enzymatic activity in different variants was based on the colorimetric method. It was applied to measure the dehydrogenase activity (DHA), where 1\% TTC (triphenyltetrazolium chloride) was used as the substrate. DHA was measured after $24 \mathrm{~h}$ of incubation at $30^{\circ} \mathrm{C}$ and at a wavelength of $485 \mathrm{~nm}$. It was expressed as mmol TPF (triphenylformazan) $24 \mathrm{~h}^{-1} \mathrm{~g}^{-1} \mathrm{dm}$ of soil [16].

Apart from that, the biochemical analyses of soil involved measurement of the acid and alkaline phosphomonoesterase activity (EC 3.1.3.2) (PAC and PAL) with the method developed by Tabatabai and Bremner [17]. The activity was measured by converting disodium phosphate tetrahydrate to nitrophenyl tetrahydrate after $1 \mathrm{~h}$ of incubation at $37^{\circ} \mathrm{C}$ and at a wavelength of $400 \mathrm{~nm}$. The results were expressed as mmol (p-nitrophenol) PNP h-1 $\mathrm{g}^{-1} \mathrm{dm}$ of soil.

Catalase activity was measured with the manometric method developed by Johnsons and Temple [18] with $0.3 \% \mathrm{H}_{2} \mathrm{O}_{2}$ as the substrate. The activity was expressed as mmol $\mathrm{H}_{2} \mathrm{O}_{2} \mathrm{~g}^{1} \mathrm{~d} \cdot \mathrm{m}$. $\mathrm{min}^{-1}$.

\section{Measuring the Biological Index of Fertility}

The biological index of soil fertility (BIF) was calculated on the basis of dehydrogenase activity (DHA) and catalase activity (CAT) and the following formula: $(\mathrm{DHA}+\mathrm{kCAT}) / 2$, where $\mathrm{k}$ is the coefficient of proportionality and equals 0.01 [19]. 


\section{Statistical Analysis}

The dynamics of variation in the microbial composition of soil and dehydrogenase activity were analysed statistically. The results underwent two-way analysis of variance with Statistica 9.1 software. The fertilisation method and the term of analyses were the factors differentiating the traits under study. The significance of differences between the pairs of factors was analysed by means of Tukey's test. Principal component analysis (PCA) was used to visualise multidimensional dependences between soil bioactivity, fertilisation methods, and terms of analyses.

\section{Results and Discussion}

\section{Nitrogenase Activity}

A 2-year field experiment conducted in 2014 and 2015 showed that PRP SOL and PRP EBV fertilisers and co-inoculation (simultaneous inoculation of plants with nodule bacteria and endophytic bacteria) applied in yellow lupine cultivation stimulated nitrogenase activity. In all fertilisation variants the activity was greater than in the control variant (Fig. 1).

The highest nitrogenase activity noted in the variants was fertilisation combined with co-inoculation. The biofixation of molecular nitrogen in these variants was 5 times greater than in the control variant or in the variant where nitrogen inoculation was applied on its own. The effect was caused both by the fertilisers and the Bacillus subtilis endophyte. There were similar results in the study by Niewiadomska [1], where the author assessed the influence of PRP SOL fertiliser and co-inoculation with bacteria of the Azospirillum genus on clover and alfalfa.
The increase in nitrogenase activity can be explained by the availability of calcium and the influence of other microelements (boron, copper, manganese, and molybdenum) in PRP SOL fertiliser. The deficit of these microelements in soil may disorder biochemical processes. Boron stimulates the formation of nodules. Copper increases their mass. Manganese increases nitrogen assimilation and protein biosynthesis. Molybdenum plays a significant role in nitrate reduction and fixation of free nitrogen by symbiotic bacteria [20]. The considerable increase in nitrogenase activity after co-inoculation can be explained by the influence of the Bacillus subtilis endophyte, which belongs to PGPR bacteria. The effect may have been caused by the indirect influence of the endophyte on plants. There have been reports of the bacteria's capacity to synthesise and secrete bioactive substances known as phytohormones [21-22]. They have a positive influence on the growth, development, and ramification of clover and alfalfa root hair. In consequence, plants become more susceptible to infections with adequate nodule bacteria of the Rhizobium and Sinorhizobium genera and to the development of populations of symbiotic bacteria in these combinations. Many studies showed that simultaneous inoculation stimulated plants. Swędrzyńska et al. [23] and Niewiadomska and Swędrzyńska [24] proved it in their laboratory studies, where Rhizobium and Azospirillum as well as Herbaspirillum and Sinorhizobium were applied. Iqbal et al. [25] noted the stimulating effect of coinoculation with Rhizobium leguminosarum and bacteria of the Pseudomonas genus in a field experiment. The use of PGPR to increase the nitrogen fixation efficiency under uncontrolled conditions often produces different results than in a laboratory. Soil is a very changeable environment, so it is usually difficult to achieve the expected result.

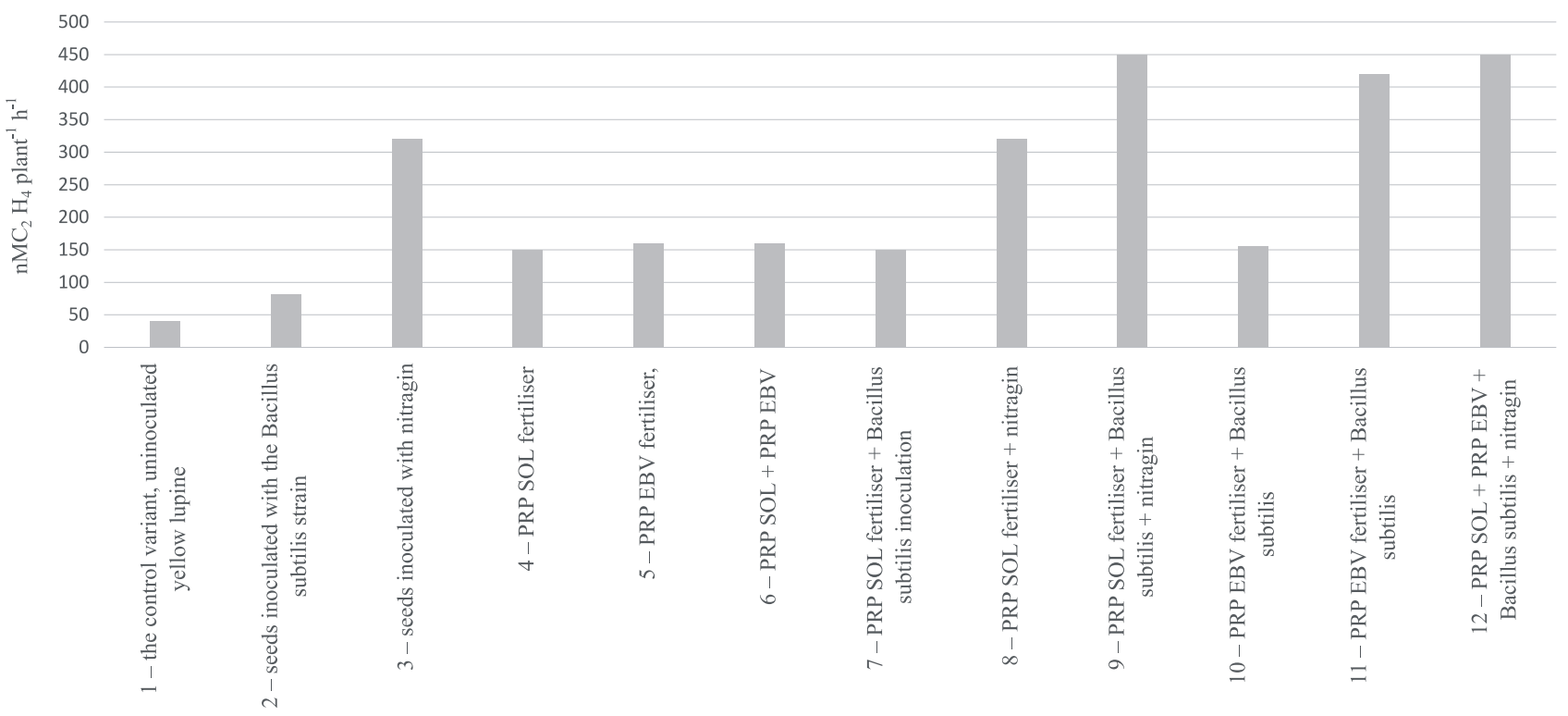

Fig. 1. Influence of fertilisation with/without co-inoculation on nitrogenase activity. 
Table 3. F-test statistical values and significance levels of the parameters of the biochemical activity of soil under yellow lupine; fertilisation and/or co-inoculation are the factors influencing the traits under. study.

\begin{tabular}{|c|c|c|c|}
\hline Parameter & $\begin{array}{c}\text { Fertilization with/without } \\
\text { coinoculation }\end{array}$ & Term & Interaction \\
\hline Catalase & $2.34^{* * *}$ & $7.99^{* * * *}$ & $5.45^{* * *}$ \\
\hline Acid phosphatasa PAC & $7.83^{* * *}$ & $39.90^{* * *}$ & $5.96^{* * *}$ \\
\hline Alkalical phosphatasa PAL & $14.45^{* * *}$ & $156.95^{* * *}$ & $21.93^{* * *}$ \\
\hline Dehydrogenases & $334.21^{* * *}$ & $186.04^{* * *}$ & $21.00^{* * *}$ \\
\hline BIF & $334.41^{* * *}$ & $186.85^{* * *}$ & \\
\hline
\end{tabular}

${ }^{* * *} \mathrm{p}=0,001,{ }^{* *} \mathrm{p}=0,01,{ }^{*} \mathrm{p}=0,05$, ns: not statistically significant

\section{Biochemical Activity of Soil}

Each habitat is characterised by a specific system of microbiological transformations. The whole system functions in a specific state of equilibrium, where a large part of processes occur regularly and are significant for soil activity [26]. Soil bioactivity, which consists of transformation of soil compounds and energy, is an inseparable element of its structure. Enzymatic and microbial activities are the most noticeable indicators of soil bioactivity [1]. They are conditioned by numerous factors, including type of soil, vegetation, depth of the soil profile, $\mathrm{pH}$, temperature, weather conditions, content of organic matter, and agrotechny [27]. In spite of the dynamic character of microbiological and biochemical properties, soil enzymes are a precise and significant indicator of soil fertility, which reflects changes occurring in it [28].

The application of fertilisers into soil causes noticeable changes in enzymatic activity. The trend and intensity of these changes depends on the type and dose of a specific enzyme [29-30]. Variation in the activity of soil enzymes reflects environmental disorders, which affect both soil and plants [31].

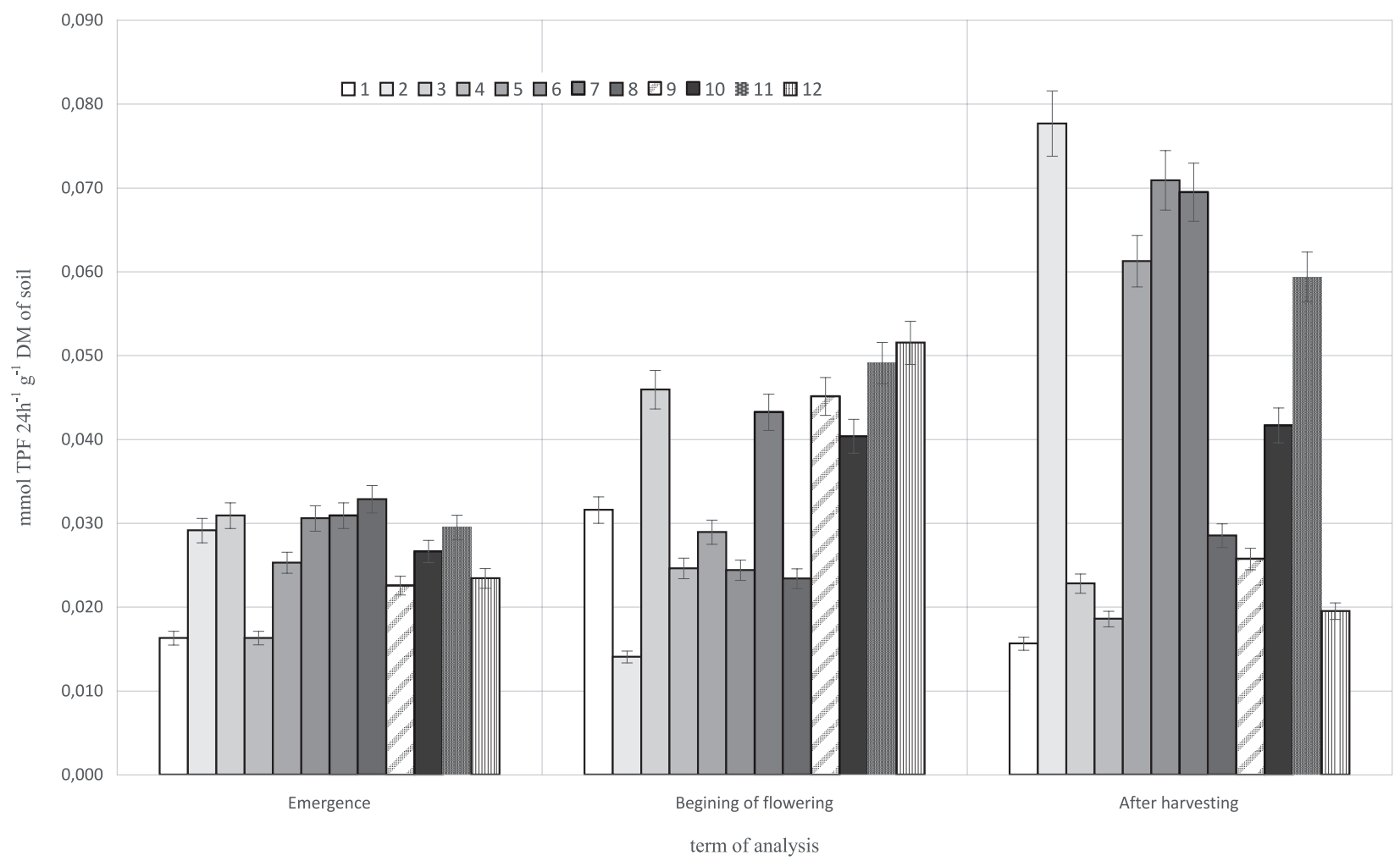

Fig. 2. Influence of fertilisation with/without co-inoculation on dehydrogenases activity: 1 - the control variant, uninoculated yellow lupine, 2 - seeds inoculated with the Bacillus subtilis strain, 3 - seeds inoculated with nitragin, 4 - PRP SOL fertiliser, 5 - PRP EBV fertiliser, 6 - PRP SOL + PRP EBV, 7 - PRP SOL fertiliser + Bacillus subtilis inoculation, 8 - PRP SOL fertiliser + nitragin, $9-$ PRP SOL fertiliser + Bacillus subtilis + nitragin, $10-$ PRP EBV fertiliser + Bacillus subtilis, $11-$ PRP EBV fertiliser + Bacillus subtilis + nitragin, 12 - PRP SOL + PRP EBV + Bacillus subtilis + nitragin.; means values \pm standard errors. 
The 2-year field experiment conducted in 2014 and 2015 showed that PRP SOL and PRP EBV fertilisers and co-inoculation (simultaneous inoculation of plants with nodule bacteria and endophytic bacteria) applied during yellow lupine cultivation stimulated the biochemical activity of soil. The trend and rate of variation in the enzymatic activity depended on the type of soil fertilisation and the method of seed inoculation.

The two-way analysis of variance showed that the active ingredient in PRP SOL and PRP EBV fertilisers and co-inoculation had highly significant influence $(\alpha \leq 0.001)$ on the biochemical activity of soil under yellow lupine (Table 3 ).

The analysis of the mean results of the dehydrogenase activity in individual experimental variants during the 2 years of the research showed that PRP SOL and PRP EBV fertilisers and co-inoculation (simultaneous seed inoculation with a strain of nodule bacteria and Bacillus subtilis) stimulated the enzyme activity. In spring, during the plants' emergence, all variants of fertilisers and seed inoculation resulted in higher dehydrogenases activity than in the control variant (Fig. 2). The highest activity of the enzyme at the first term of analyses was noted in the variant where PRP SOL fertiliser was applied in combination with seed inoculation with nitrogen. The dehydrogenase activity was slightly lower in the variant where PRP SOL fertiliser was applied in combination with seed inoculation with Bacillus subtilis bacteria. During the plants' florescence the dehydrogenases activity in variants 11 (PRP EBV fertiliser combined with co-inoculation) and 12 (PRP SOL + PRP EBV fertilisers combined with co-inoculation) was significantly higher than in the control variant. All the fertilisation variants were proven to stimulate dehydrogenase activity after harvesting.

In view of the fact that when dehydrogenases are released from cells into soil they quickly become inactivated, we can say that their activity in soil is directly related to the metabolic activity of the whole population of microorganisms. The activity of this group of enzymes is a good indicator of the microbial activity in soil. The study on the influence of PRP SOL fertiliser on dehydrogenase activity under a rapeseed plantation also showed that the enzyme was stimulated [32].

Srinivasan et al. [33] observed that fertilisers containing nitrogen, phosphorus, and potassium had positive influence on the content of dehydrogenases in soil. Swędrzyńska et al. [34] obtained analogical results in their study on similar bioconditioners. According to Kumar [35], boron increases dehydrogenase activity. Taran at al. [36] observed that molybdenum stimulated the production of these enzymes by the root nodules of legumes and discussed the possibility of a positive correlation between titanium and soil biochemistry.

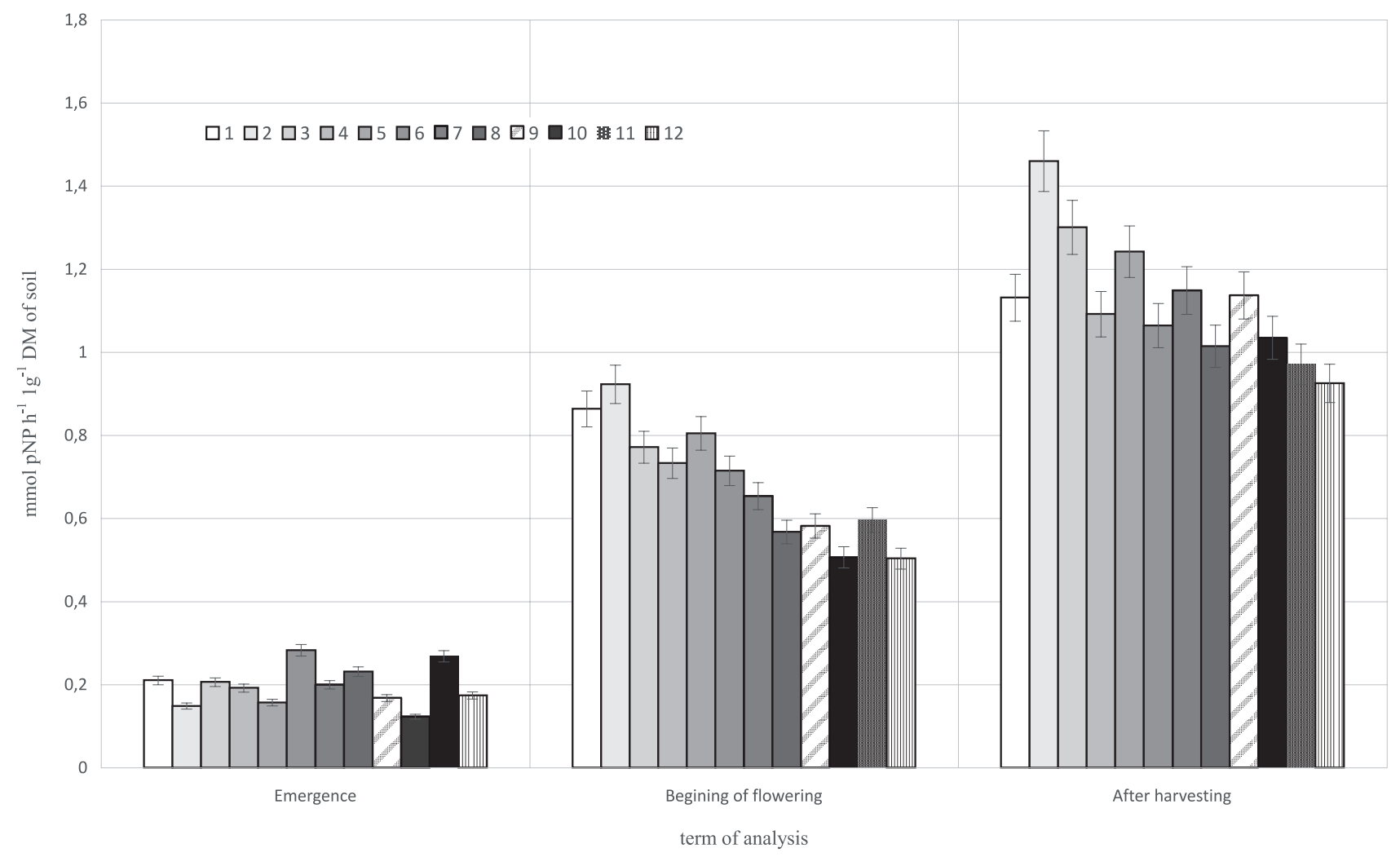

Fig. 3. Influence of fertilisation with/without co-inoculation on acid phosphatase activity: 1 - the control variant, uninoculated yellow lupine, 2 - seeds inoculated with the Bacillus subtilis strain, 3 - seeds inoculated with nitragin, 4 - PRP SOL fertiliser, 5 - PRP EBV fertiliser, 6 - PRP SOL + PRP EBV, 7 - PRP SOL fertiliser + Bacillus subtilis inoculation, 8 - PRP SOL fertiliser + nitragin, 9 - PRP SOL fertiliser + Bacillus subtilis + nitragin, $10-$ PRP EBV fertiliser + Bacillus subtilis, $11-$ PRP EBV fertiliser + Bacillus subtilis + nitragin, 12 - PRP SOL + PRP EBV + Bacillus subtilis + nitragin.; means values \pm standard errors. 
Acid and alkaline phosphatase (PAC and PAL) were another group of enzymes used in the research to test the quality of soil after applying PRP SOL fertiliser into it and spraying leaves with PRP EBV fertiliser in combination with or without co-inoculation. During the entire growth period the acid phosphatase activity in most of the experimental variants was lower than in the control variant (Fig. 3). The lowest activity was observed during the plants' emergence. During florescence total enzymatic activity increased considerably. When the fertilisers and different inoculation variants were applied, the activity was lower than in the control variant. At this period of analyses the acid phosphatase activity in variants 10 (EBV fertiliser applied to leaves and seed inoculation with Bacillus subtilis bacteria) and 12 (PRP SOL fertiliser applied into soil + PRP EBV fertiliser applied to leaves in combination with seed inoculation) was $42 \%$ lower than in the control variant. After harvesting there was a similar decrease in the acid phosphatase activity, as compared with the control variant. The Bacillus subtilis endophyte improved the assimilation of nitrogen, phosphorus, potassium and microelements not only by increasing the surface of roots but also by stimulation of ion uptake systems.

During the plants' emergence the alkaline phosphatase activity differed from the acid phosphatase activity. The highest alkaline phosphatase activity was observed in all the variants where PRP SOL and PRP EBV fertilisers were applied in combination with each inoculation variant (Fig. 4). The activity of the enzyme was higher in variants 3 (seeds inoculated with nitragin) and 5 (PRP EBV fertiliser applied to leaves) at the third term of analyses, i.e., after harvesting.

During the plants' florescence and after harvesting the acid phosphatase activity and alkaline phosphatase activity were similar. In a large part of the analyses their activity was lower than in the control variant when PRP SOL and PRP EBV fertilisers were applied in combination with co-inoculation. This effect was probably caused by fertilisation and co-inoculation, as they provided necessary elements for plants and increased the assimilation of nutrients in soil. Niewiadomska [1] observed an analogical effect in the study on alfalfa, where the PRP SOL fertiliser containing phosphorus, potassium, zinc, boron, molybdenum, and other elements decreased the catalytic activity of the enzyme by triggering compounds unavailable to plants. There were similar results in the studies by Nahas [37] and Laishram et al. [28]. Lemanowicz and Koper [38] observed greater activity of these enzymes in the experimental variant without phosphorus fertilisation. Rotaru [39] found that the deficit of this macroelement stimulated plants to secrete phosphatases. Erel at al. [40] confirmed the dependence between

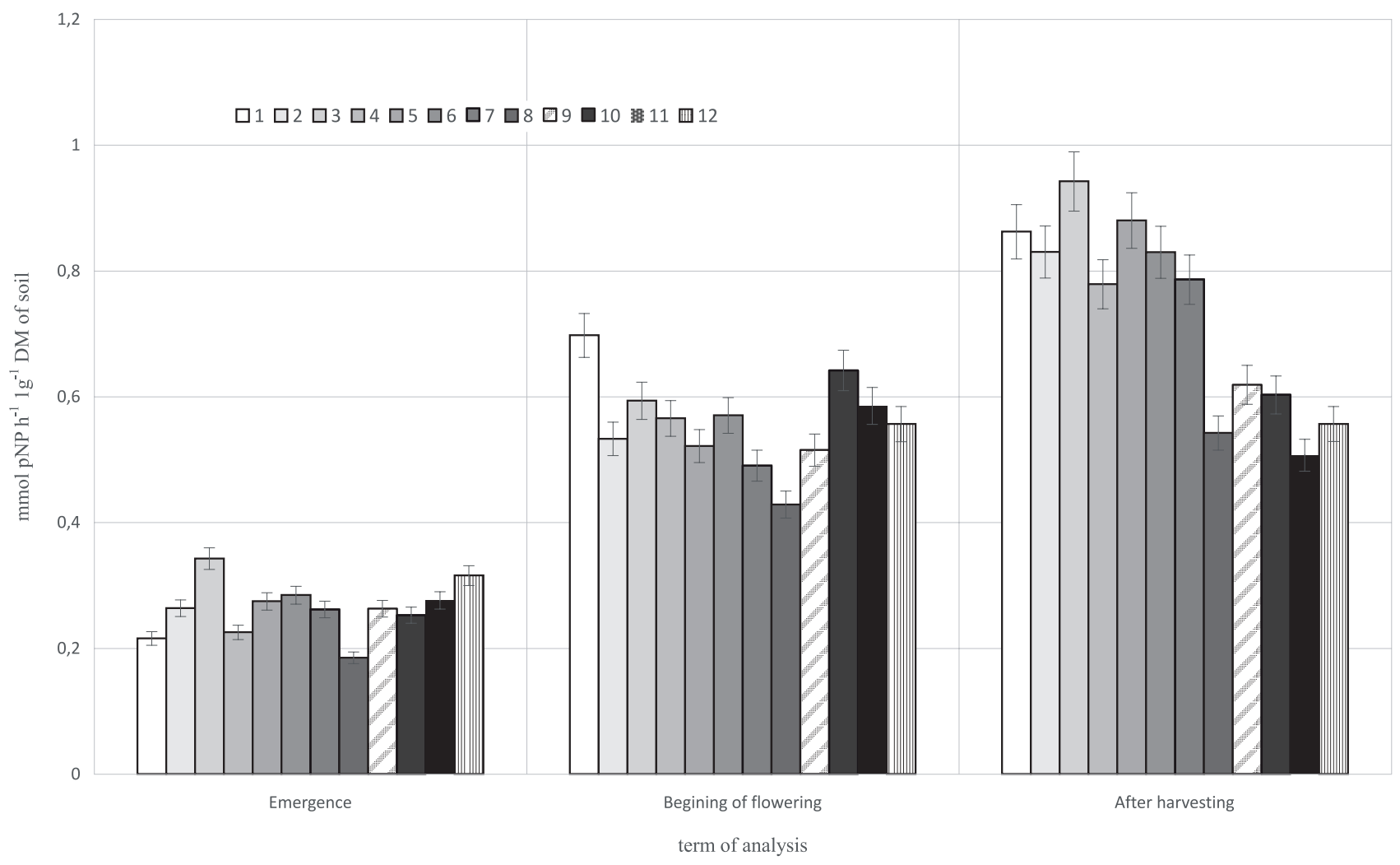

Fig. 4. Influence of fertilisation with/without co-inoculation on alkaline phosphatase activity: 1 - the control variant, uninoculated yellow lupine, 2 - seeds inoculated with the Bacillus subtilis strain, 3 - seeds inoculated with nitragin, 4 - PRP SOL fertiliser, 5 - PRP EBV fertiliser, 6 - PRP SOL + PRP EBV, 7 - PRP SOL fertiliser + Bacillus subtilis inoculation, 8 - PRP SOL fertiliser + nitragin, $9-$ PRP SOL fertiliser + Bacillus subtilis + nitragin, $10-$ PRP EBV fertiliser + Bacillus subtilis, $11-$ PRP EBV fertiliser + Bacillus subtilis + nitragin, 12 - PRP SOL + PRP EBV + Bacillus subtilis + nitragin.; means values \pm standard errors. 
the uptake of phosphorus, yield, and phosphomonoesterase activity.

Catalase is another enzyme that can be used to monitor soil quality. In comparison with the control variant, the catalase activity increased significantly in all the variants and at all terms of the experiment (Fig. 5). The highest activity of this enzyme was observed during the plants' florescence in variants 10 (PRP EBV fertiliser applied to leaves and lupine seeds inoculated with Bacillus subtilis bacteria) and 9 (PRP SOL fertiliser applied to soil and co-inoculation with the same bacteria). At the same time of analyses there was also significantly higher activity in the variant where seeds were inoculated with nitragin only. There was a similar effect of nitragin on the catalase activity after harvesting (Fig. 5).

The highest catalase activity was observed in all the fertilisation and co-inoculation variants at the beginning of yellow lupine florescence (Fig. 5). Niewiadomska [1] obtained analogical results in the study on catalase activity, where the PRP SOL fertiliser and co-inoculation with bacteria of the Azospirillum genus were applied to clover and alfalfa. Swedrzyńska and Jankowska [41] observed dependence between the catalase activity and phases of plant development. Other researchers failed to report any variation in seasonal catalase activity, maintaining that the activity of this enzyme was closely connected with vegetation cover and depended on the root system of the cultivated plant [42].
The biological index of fertility (BIF) is strictly correlated with catalase activity. Likewise, the highest value of the index was observed in all fertilisation variants at the beginning of the plants' florescence (Fig. 6). It is noteworthy that at the beginning of the plants' emergence the values of the index ranged from 2.3 in the control variant to 16.8 in the variant where PRP SOL fertiliser and nitrogen were applied. During the plants' florescence the values of the index ranged from 45.9 in the control variant to 83.5 in the variant where PRP EBV fertiliser and seed inoculation with Bacillus subtilis were applied.

The BIF was calculated on the basis of the dehydrogenases and catalase activity. It was significantly stimulated by different variants of soil fertilisation and yellow lupine inoculation (Fig. 6). It is estimated that the index value ranges from 1 to 17 in soil under cereals and from 20 to 80 in soil under legumes, depending on soil fertility. Fertility directly depends on organic matter, which carries nutrients and influences the physical chemical and biological properties of soil. The transformation of organic substances would not be possible without soil microorganisms and their enzymes.

\section{Microbial Activity}

The count of microorganisms is a major microbiological index. The dynamics of variation in the count of microorganisms may be affected by cultivation,

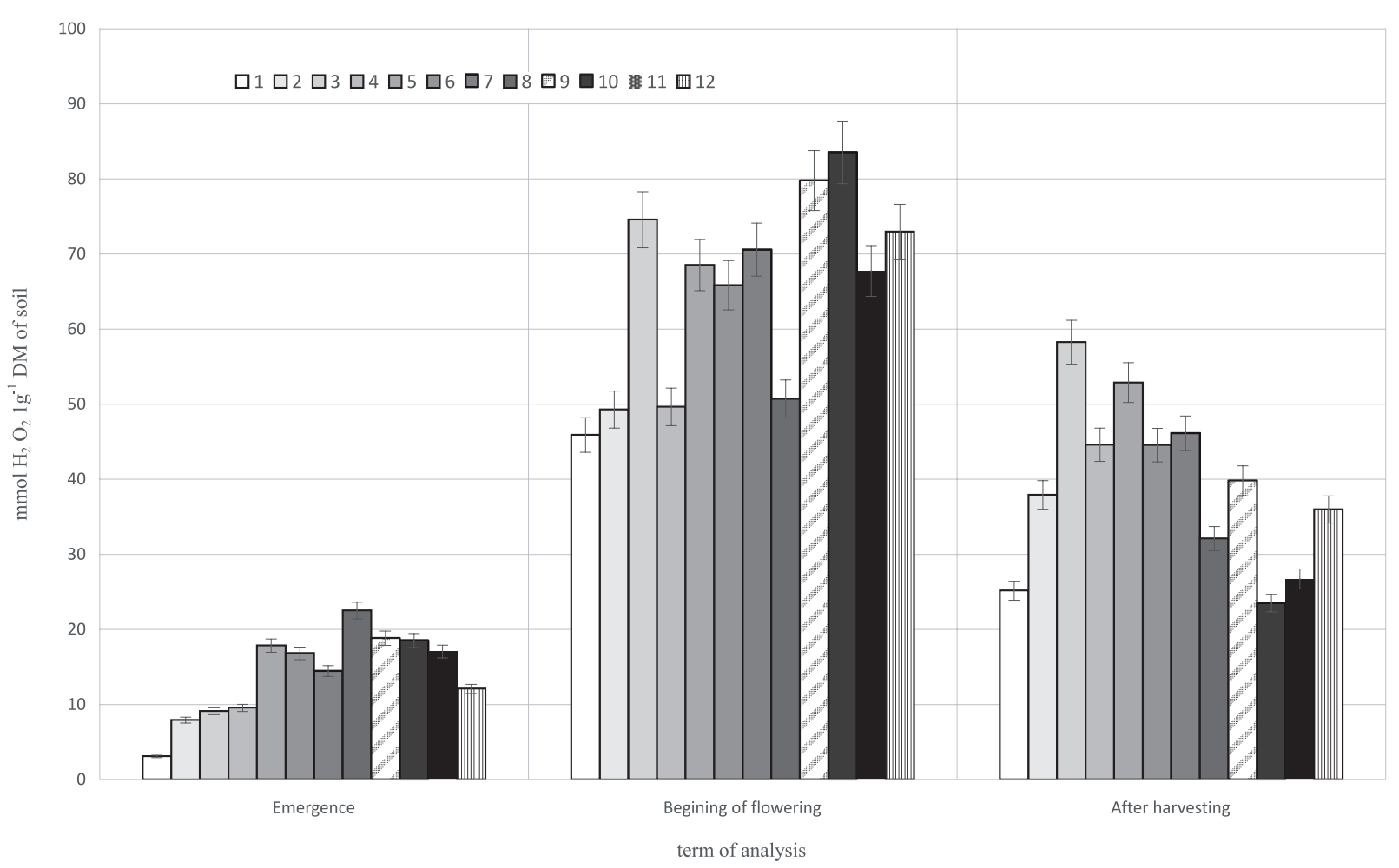

Fig. 5. Influence of fertilisation with/without co-inoculation on the catalase activity: 1 - the control variant, uninoculated yellow lupine, 2 - seeds inoculated with the Bacillus subtilis strain, 3 - seeds inoculated with nitragin, 4 - PRP SOL fertiliser, 5 - PRP EBV fertiliser, 6 - PRP SOL + PRP EBV, 7 - PRP SOL fertiliser + Bacillus subtilis inoculation, 8 - PRP SOL fertiliser + nitragin, 9 - PRP SOL fertiliser + Bacillus subtilis + nitragin, $10-$ PRP EBV fertiliser + Bacillus subtilis, $11-$ PRP EBV fertiliser + Bacillus subtilis + nitragin, $12-$ PRP $\mathrm{SOL}+\mathrm{PRP} \mathrm{EBV}+$ Bacillus subtilis + nitragin; means values \pm standard errors. 


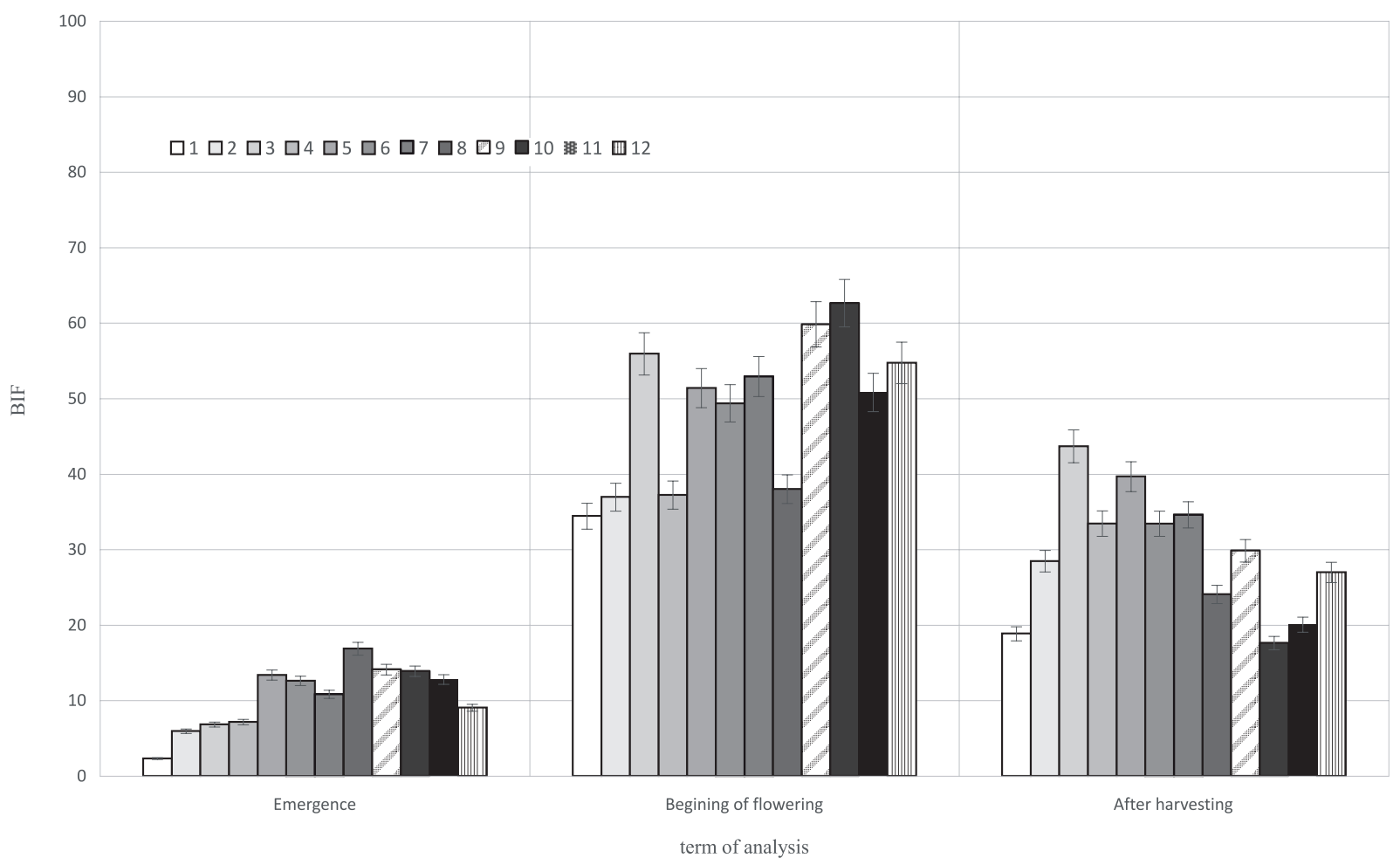

Fig. 6. Influence of fertilisation with/without co-inoculation on BIF: 1 - the control variant, uninoculated yellow lupine, 2 - seeds inoculated with the Bacillus subtilis strain, 3 - seeds inoculated with nitragin, 4 - PRP SOL fertiliser, 5 - PRP EBV fertiliser, 6 - PRP SOL + PRP EBV, 7 - PRP SOL fertiliser + Bacillus subtilis inoculation, 8 - PRP SOL fertiliser + nitragin, 9 - PRP SOL fertiliser + Bacillus subtilis + nitragin, $10-$ PRP EBV fertiliser + Bacillus subtilis, $11-$ PRP EBV fertiliser + Bacillus subtilis + nitragin, $12-$ PRP $\mathrm{SOL}+\mathrm{PRP} \mathrm{EBV}+$ Bacillus subtilis + nitragin.; means values \pm standard errors.

fertilisation, and crop protection products [43]. The activity of soil microorganisms, their quality, and quantity are also influenced by the content of organic matter, nitrogen compounds, macro- and microelements, water, oxygen, $\mathrm{pH}$, and temperature [44]. The availability of nutrients that can be easily assimilated favours the intensive proliferation of soil microorganisms. However, allelopathic substances secreted by plant roots and compounds produced by other groups of organisms may cause adverse interactions between them [45].

The two-way analysis of variance showed that the active ingredient in PRP SOL and PRP EBV fertilisers and co-inoculation had highly significant influence $(\alpha \leq 0.001)$ on the count of selected groups of microorganisms under yellow lupine (Table 4). The analysis showed variation in the total bacterial count during the growth of yellow lupine and in consequence of applying PRP SOL and PRP EBV fertilisers with or without co-inoculation. The highest total bacterial count was noted in early spring, immediately after the plants began to grow (Fig. 7). Simultaneously, the analysis showed that during this period the count of bacterial colonies in all the fertilisation variants was greater than in the control variant.

Swędrzyńska at al. [46] also observed that in comparison with the control variant, the total bacterial count was stimulated at the initial period following mineral fertilisation. Niewiadomska et al. [32] proved that the term of analysis and type of fertiliser influenced variation in the total bacterial count in soil. During the plants' emergence the highest total bacterial count was noted in the variant where seeds were inoculated with the Bacillus subtilis endophyte. Co-inoculation with these PGPR may indirectly affect the count and increase the activity of other soil microorganisms. Growth-promoting bacteria may have direct influence on plants, because they facilitate the uptake of nutrients from the environment and production of phytohormones. They may also have indirect influence by reducing harmful effects and protecting plants from pathogenic organisms [47].

Table 4. F-test statistical values and the significance levels of the parameters of the biochemical activity of soil under yellow lupine; fertilisation and/or co-inoculation are the factors influencing the traits under study.

\begin{tabular}{|c|c|c|c|}
\hline Parameter & $\begin{array}{c}\text { Fertilization } \\
\text { with/without } \\
\text { coinoculation }\end{array}$ & Term & $\begin{array}{c}\text { Interac- } \\
\text { tion }\end{array}$ \\
\hline Total number of bacteria & $7.21^{* * *}$ & $9.74^{* * *}$ & $6.31^{* * *}$ \\
\hline Moduls & $39.93^{* * *}$ & $234.31^{* * *}$ & $11.09^{* * *}$ \\
\hline Actinobacteria & $93.67^{* * *}$ & $118.73^{* * *}$ & $40.97^{* * *}$ \\
\hline Oligotroph & $11.54^{* * *}$ & $41.42^{* * *}$ & $2.76^{* * *}$ \\
\hline Copiotroph & $8.94^{* * *}$ & $22.24^{* * *}$ & $4.56^{* * *}$ \\
\hline
\end{tabular}




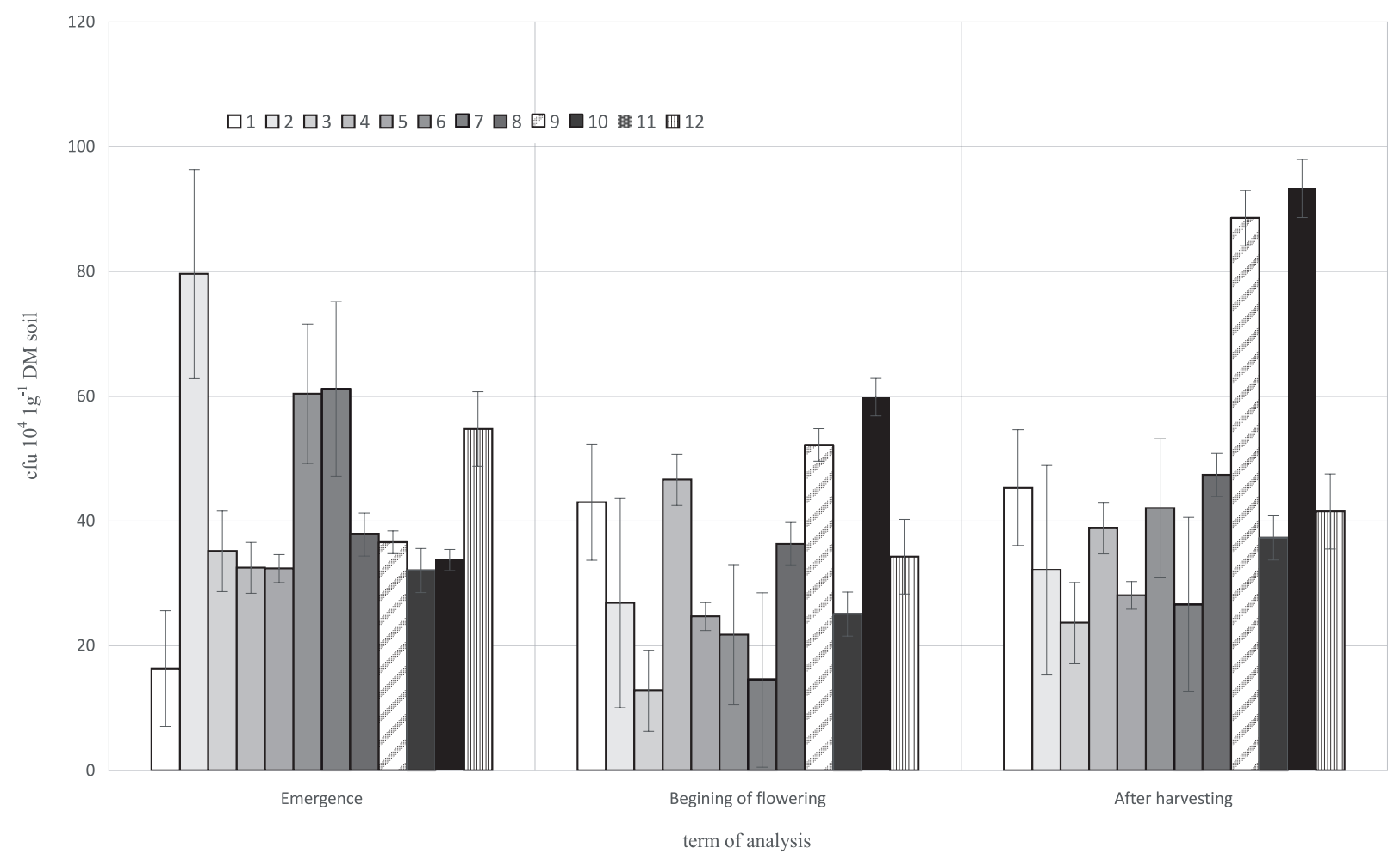

Fig. 7. Influence of fertilisation with/without co-inoculation on the total bacterial count: 1 - the control variant, uninoculated yellow lupine, 2 - seeds inoculated with the Bacillus subtilis strain, 3 - seeds inoculated with nitragin, 4 - PRP SOL fertiliser, 5 - PRP EBV fertiliser, 6 - PRP SOL + PRP EBV, 7 - PRP SOL fertiliser + Bacillus subtilis inoculation, 8 - PRP SOL fertiliser + nitragin, $9-$ PRP SOL fertiliser + Bacillus subtilis + nitragin, $10-$ PRP EBV fertiliser + Bacillus subtilis, $11-$ PRP EBV fertiliser + Bacillus subtilis + nitragin, 12 - PRP SOL + PRP EBV + Bacillus subtilis + nitragin.; means values \pm standard errors.

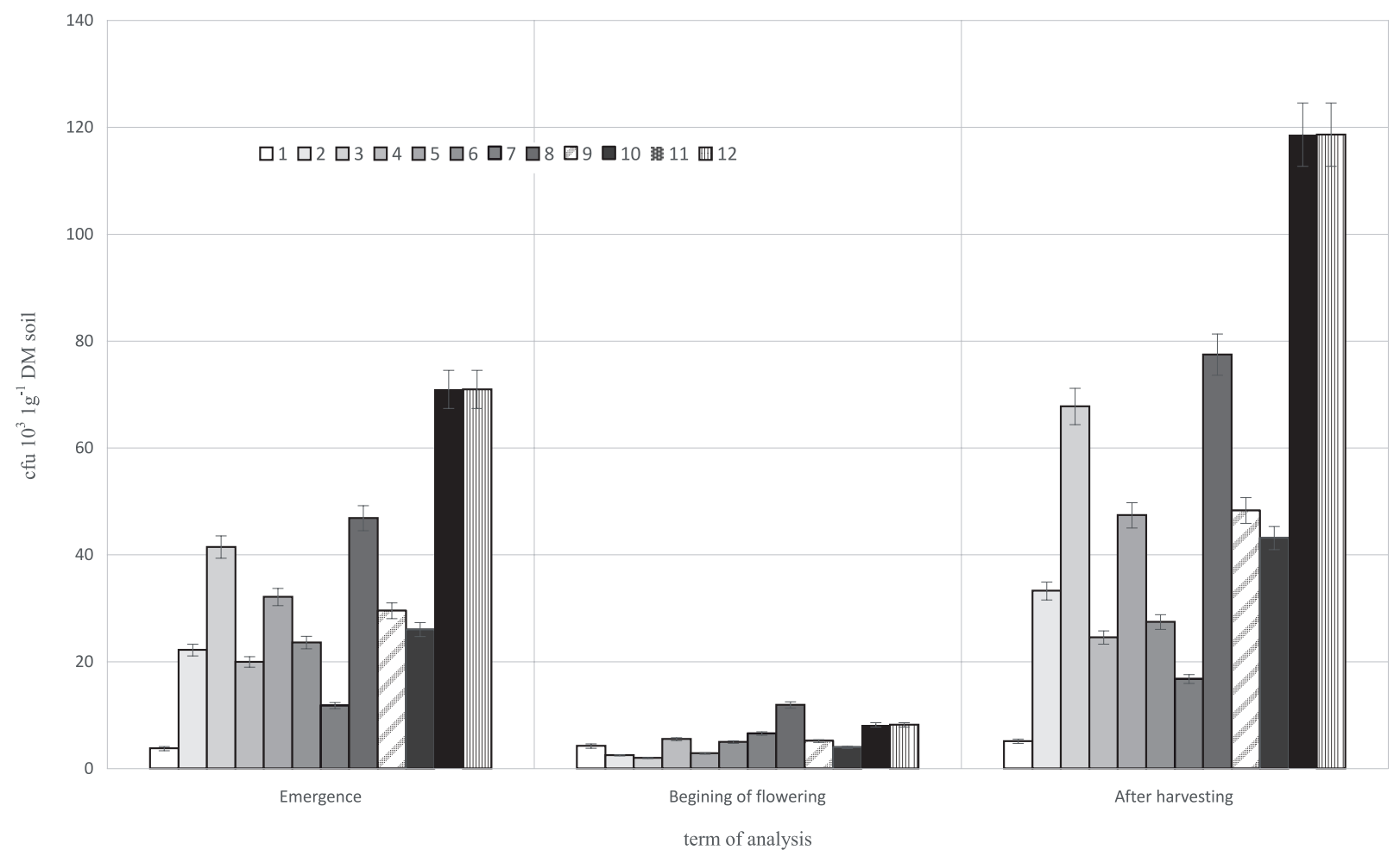

Fig. 8. Influence of fertilisation with/without co-inoculation on the count of moulds: 1 - the control variant, uninoculated yellow lupine, 2 - seeds inoculated with the Bacillus subtilis strain, 3 - seeds inoculated with nitragin, 4 - PRP SOL fertiliser, 5 - PRP EBV fertiliser, 6- PRP SOL + PRP EBV, 7 - PRP SOL fertiliser + Bacillus subtilis inoculation, 8 - PRP SOL fertiliser + nitragin, 9 - PRP SOL fertiliser + Bacillus subtilis + nitragin, $10-$ PRP EBV fertiliser + Bacillus subtilis, $11-$ PRP EBV fertiliser + Bacillus subtilis + nitragin, $12-$ PRP $\mathrm{SOL}+\mathrm{PRP} \mathrm{EBV}+$ Bacillus subtilis + nitragin.; means values \pm standard errors. 


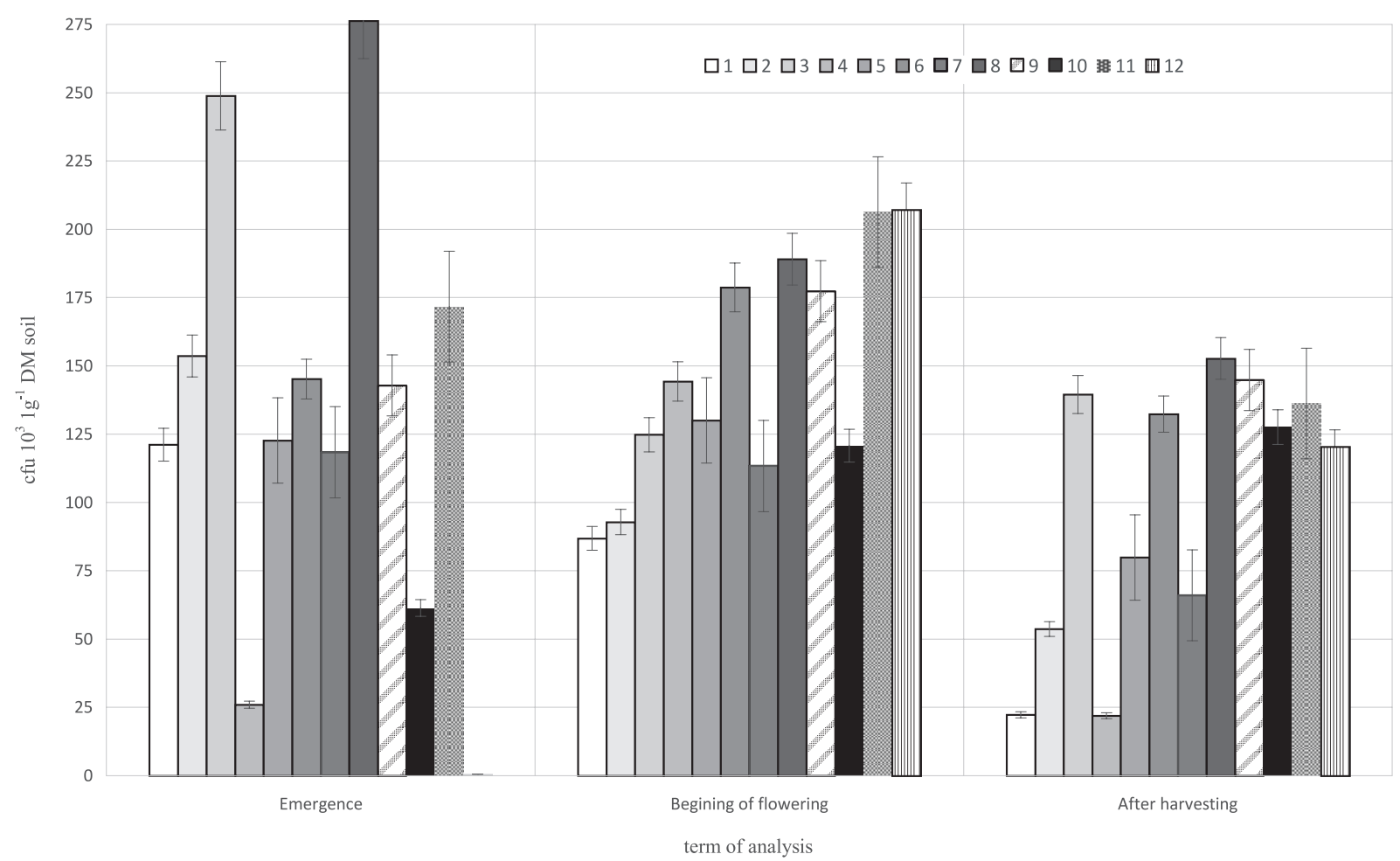

Fig. 9. Influence of fertilisation with/without co-inoculation on the count of Actinobacteria: 1 - the control variant, uninoculated yellow lupine, 2 - seeds inoculated with the Bacillus subtilis strain, 3 - seeds inoculated with nitragin, 4 - PRP SOL fertiliser, 5 - PRP EBV fertiliser, 6 - PRP SOL + PRP EBV, 7 - PRP SOL fertiliser + Bacillus subtilis inoculation, 8 - PRP SOL fertiliser + nitragin, $9-$ PRP SOL fertiliser + Bacillus subtilis + nitragin, $10-$ PRP EBV fertiliser + Bacillus subtilis, $11-$ PRP EBV fertiliser + Bacillus subtilis + nitragin, 12 - PRP SOL + PRP EBV + Bacillus subtilis + nitragin.; means values \pm standard errors.

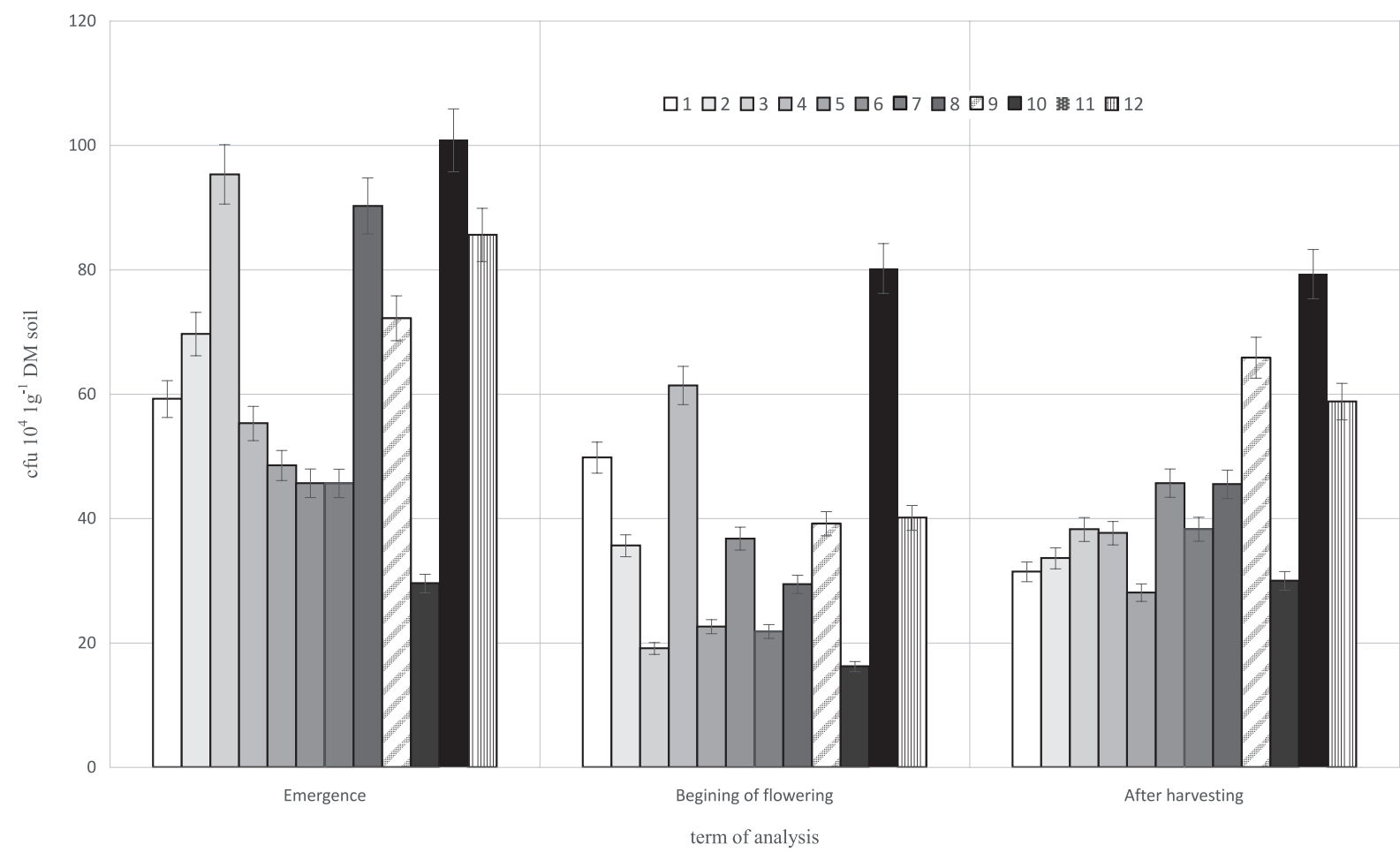

Fig. 10. Influence of fertilisation with/without co-inoculation on the count of oligotrophs: 1 - the control variant, uninoculated yellow lupine, 2 - seeds inoculated with the Bacillus subtilis strain, 3 - seeds inoculated with nitragin, 4 - PRP SOL fertiliser, 5 - PRP EBV fertiliser, 6 - PRP SOL + PRP EBV, 7 - PRP SOL fertiliser + Bacillus subtilis inoculation, 8 - PRP SOL fertiliser + nitragin, $9-$ PRP SOL fertiliser + Bacillus subtilis + nitragin, $10-$ PRP EBV fertiliser + Bacillus subtilis, $11-$ PRP EBV fertiliser + Bacillus subtilis + nitragin, 12 - PRP SOL + PRP EBV + Bacillus subtilis + nitragin.; means values \pm standard errors. 


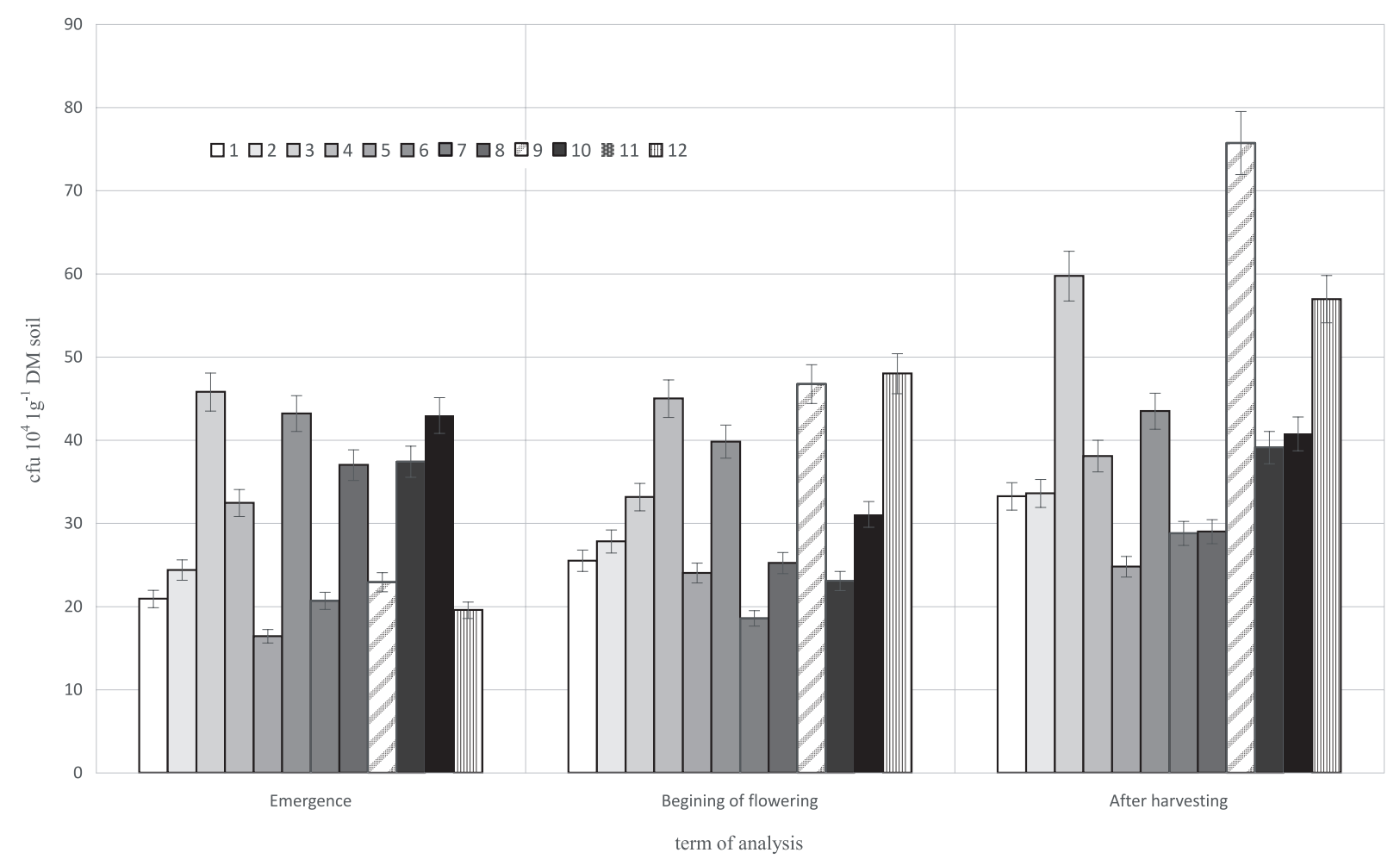

Fig. 11. Influence of fertilisation with/without co-inoculation on the count of copiotrophs: 1 - the control variant, uninoculated yellow lupine, 2 - seeds inoculated with the Bacillus subtilis strain, 3 - seeds inoculated with nitragin, 4 - PRP SOL fertiliser, 5 - PRP EBV fertiliser, 6 - PRP SOL + PRP EBV, 7 - PRP SOL fertiliser + Bacillus subtilis inoculation, 8- PRP SOL fertiliser + nitragin, 9- PRP SOL fertiliser + Bacillus subtilis + nitragin, 10 - PRP EBV fertiliser + Bacillus subtilis, $11-$ PRP EBV fertiliser + Bacillus subtilis + nitragin, 12 - PRP SOL + PRP EBV + Bacillus subtilis + nitragin.; means values \pm standard errors.

At the beginning of the plants' florescence and after harvesting, the highest count of these microorganisms was noted in variants 9 (PRP SOL fertiliser combined with co-inoculation) and 11 (PRP EBV fertiliser applied to leaves and combined with co-inoculation). The increase in the count of microorganisms after co-inoculation was also observed by Klama et al. [48] and Niewiadomska [1] in their studies.

The count of moulds depended on the phase of plant development and type of fertilisation (Fig. 8). The synthesis of the results from the 2 years of the experiment showed that the count of moulds increased at the phase of yellow lupine emergence and after harvesting. At both phases the count of moulds was significantly greater in all the fertilisation variants than in the control variant. The highest count of moulds was noted after harvesting in variants 9 (PRP SOL fertiliser combined with co-inoculation) and 12 (PRP SOL and PRP EBV fertilisers combined with coinoculation). There were similar dependences observed during the plants' emergence. The count of moulds was very low during the plants' florescence. Pandey et al. [49] proved that when the conditions were favourable for the development of bacteria and Actinobacteria, the development of moulds was strongly inhibited. These findings were also confirmed in a study by Borowiak at al. [7], who explained that the low count of moulds at specific phases of plant development was caused by the competition of other groups of microorganisms.
The research showed that Actinobacteria were the most numerous at the phase of the plants' emergence, especially in variants 8 (PRP SOL fertiliser and inoculation with nitragin) and 3 (seeds inoculated with nitragin; Fig. 9). At the beginning of the plants' florescence, fertilisation significantly stimulated the count of Actinobacteria in variants 11 (PRP EBV fertiliser applied to leaves and combined with co-inoculation) and 12 (PRP SOL and PRP EBV fertilisers combined with co-inoculation).

The count of oligotrophs and copiotrophs also depended on the phase of plant development and the fertilisation method. The highest count of oligotrophs was noted at the phase of the plants' emergence in variants 3 (seeds inoculated with nitragin), 11 (PRP EBV fertiliser applied to leaves and combined with co-inoculation), and 12 (PRP SOL and PRP EBV fertilisers combined with coinoculation; Fig. 10).

The count of copiotrophs was similar to the count of oligotrophs during the whole period of plant growth. The highest count of copiotrophs was noted after harvesting in the variant where PRP SOL fertiliser was combined with co-inoculation (Fig. 11). The intensive development of the groups of microorganisms under study (total bacterial count, moulds, Actinobacteria, oligotrophs, and copiotrophs) in consequence of co-inoculation or inoculation with the endophyte on its own may have been caused by the properties of the endophyte applied in the experiment. Bacillus subtillis bacteria, which were used 
for co-inoculation, are characterised by rapid growth and high secretion of proteins [50]. Numerous studies have shown these microorganisms to exhibit antagonism toward moulds [51]. Non-pathogenic bacteria effectively inhibit the growth of pathogens because they secrete various substances, interact, and exhibit complementary mechanisms [52]. These bacteria colonize plant roots and form a biofilm around them. They secrete hydrogen cyanide, siderophores (including pyoverdine, which limits access of the pathogen to iron), salicylic acid, peptidases, and lytic enzymes, which break glycosidic bonds [53]. Bacillus subtilis bacteria are known to be antagonistic to fungi of the following genera: Fusarium, Rhizoctonia, Phytophthora, and Pythium. They also stimulate the growth of plants [54].

Bacteria of the Bacillus genus, which belong to the PGPR group, are capable of synthesising such organic acids as: citric, lactic, succinic, and malic. Their activity enables soil microorganisms and plants to gain access to aluminium phosphate and iron phosphate in low $\mathrm{pH}$ soils and access to calcium phosphate in alkaline $\mathrm{pH}$ soils. They form complexes with these compounds and release an assimilable form of phosphorus. Acids increase the availability of phosphorus by blocking the places where it is bound on the surface of soil particles [55].

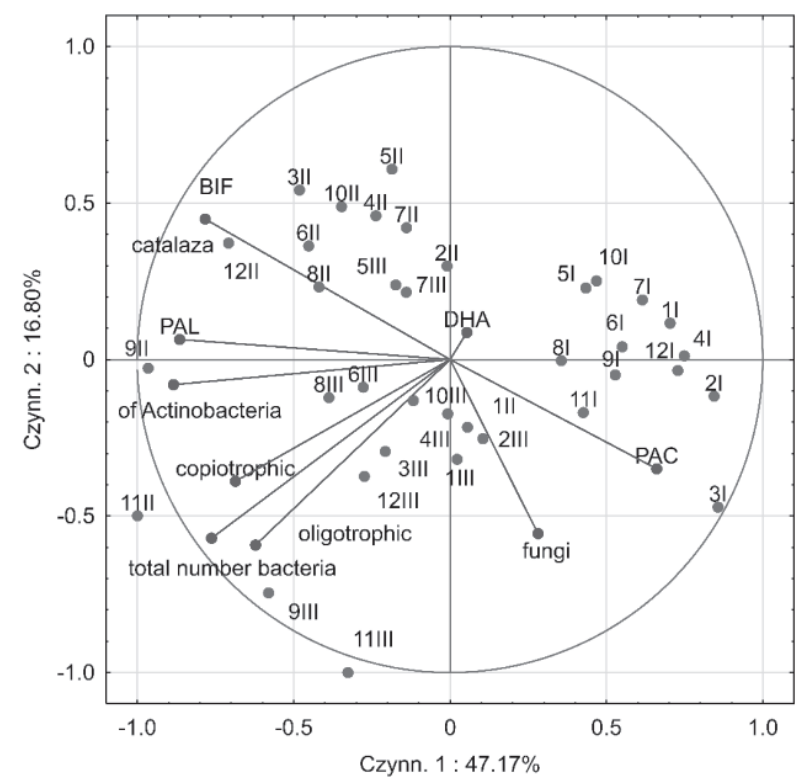

Fig. 12. Dependences observed after fertilisation with/without co-inoculation in 2014; explanation for Figs 12-13: 1 - the control variant, uninoculated yellow lupine, 2 - seeds inoculated with the Bacillus subtilis strain, 3 - seeds inoculated with nitragin, $4-$ PRP SOL fertiliser, 5 - PRP EBV fertiliser, 6 - PRP SOL + PRP EBV, 7 - PRP SOL fertiliser + Bacillus subtilis inoculation, 8 PRP SOL fertiliser + nitragin, $9-$ PRP SOL fertiliser + Bacillus subtilis + nitragin, $10-$ PRP EBV fertiliser + Bacillus subtilis, 11 - PRP EBV fertiliser + Bacillus subtilis + nitragin, 12 - PRP $\mathrm{SOL}+\mathrm{PRP} \mathrm{EBV}+$ Bacillus subtilis + nitragin; I - $1^{\text {st }}$ term - the plants' emergence, II - $2^{\text {nd }}$ term - the beginning of florescence, III $-3^{\text {rd }}$ term - after harvesting.
The dependences between the count of microorganisms and soil enzymatic activity in individual experimental variants at the terms of analyses were illustrated by means of principal component analysis (PCA) for 2014 (Fig. 12) and 2015 (Fig. 13). During the first year of the research the first principal component explained $47.17 \%$ of the dependences, whereas the other principal component explained $16.8 \%$ of the dependences. In total, they explained $63.97 \%$ of variability. During the second year of the research they explained $50.12 \%$ and $18.63 \%$ of variability, respectively, i.e. $68.77 \%$ of total variability.

Both in 2014 and 2015 there were strong dependences between soil fertility (BIF) and catalase activity during the period of the plants' florescence and after harvesting, when PRP SOL and PRP EBV fertilisers were applied in combination with co-inoculation. This proved that fertilisation stimulated soil productivity. In 2014 there was strong positive dependence between alkaline phosphatase (PAL) and Actinobacteria as well as the count of copiotrophs, oligotrophs, and total bacterial count. In 2015 there were negative correlations between the groups of organisms under study and soil enzymatic activity. These dependences may have been caused by unfavourable weather conditions (Table 2). In 2015 there was lower rainfall. It reduced soil humidity, which significantly influenced enzymatic activity and the count of Actinobacteria and moulds in the soil. Lower content of water inhibits the development of some groups of microorganisms. It decreases their count and the count of inductive enzymes, which are secreted into soil by microorganisms. Diverse dynamics of microbiological variation during the growth period was confirmed by Swędrzyńska and Jankowska [41]. Swędrzyńska and Grześ [56] observed dependence between the dehydrogenase activity, soil temperature, water content, and microorganism count.

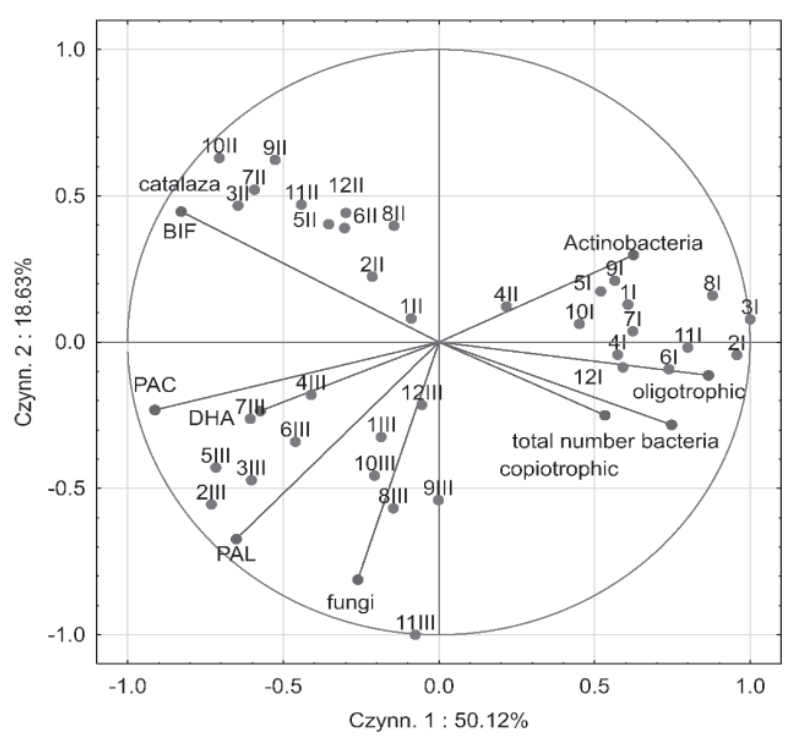

Fig. 13. Dependences observed after fertilisation with/without co-inoculation in 2015. 


\section{Conclusions}

Our research was premised on the need to thoroughly investigate how PRP SOL and PRP EBV fertilisers on their own as well as the fertilisers combined with co-inoculation influenced biological nitrogen fixation, microbial variation, and biochemical changes of soil under a legume. The plant is one of the elements in the entire biocoenotic system. All changes that take place during the growth of plants are reflected by the properties of the group of coexisting soil microorganisms.

The findings concerning the influence of PRP SOL fertiliser applied to soil, PRP EBV fertiliser sprayed onto leaves, and co-inoculation led to the following conclusions:

- The PRP SOL and PRP EBV fertilisers combined with co-inoculation stimulated the count of the soil microorganisms under study (total bacterial count, Actinobacteria, moulds, oligotrophs, and copiotrophs). There was higher count of microorganisms in the variants where PRP SOL and PRP EBV fertilisers were applied in combination with co-inoculation than in the variants where PRP SOL and PRP EBV fertilisers were applied on their own.

- There was high variability in soil enzymatic activity during plant growth. However, the findings of the research on the soil enzymatic activity confirmed the positive effect of PRP SOL and PRP EBV fertilisers with or without co-inoculation. The positive influence (high statistical significance) of the factor was mostly observed in the acid phosphatase and catalase activity. PRP SOL and PRP EBV fertilisers with or without co-inoculation reduced the acid phosphatase activity and increased catalase activity (especially during the plants' emergence). This fact proves that the fertilisers had a positive influence on soil and plants.

- Co-inoculation and PRP SOL and PRP EBV fertilisers had positive influence on biological nitrogen fixation by bacteria of the Rhizobium genus. The success of co-inoculation in the field experiment may have been caused by the fact that the inoculant was applied to the seeds of legumes together with endophytic bacteria and nitrogen. This method of application facilitated the entering of a large amount of bacteria directly to the seedlings' rhizosphere. In consequence, it increased the chance of the inoculant bacteria to make effective symbiosis.

In order to make a definite conclusion concerning the influence of PRP SOL and PRP EBV fertilisers on all types of soils it would be necessary to investigate the influence of the fertilisers on the biological and chemical activity of soil and the yield of other crops, grown on different soils. In view of the long-term use of fertilisers it would be recommended to conduct further research to confirm the positive effect of fertilisation on soil fertility (BIF).

\section{References}

1. NIEWIADOMSKA A. Assessment of the impact of PRP SOL fertiliser and co-inoculation on the process diazotrophy, biological and chemical properties of soil and the crop condition under clover and alfalfa cultivation. $\mathrm{Nr}$ 462. Poznań. Publisher. UP in Poznań. ISBN 978-83-7160710-3, 106, 2013.

2. OWEN D., WILLIAMS A.P., GRIFFITH G.W., WITHERS P.J.A. Use of commercial bio-inoculants to increase agricultural production through improved phosphrous acquisition. Appl. Soil Ecol. 86, 41, 2015.

3. SANTOYO G., OROZCO-MOSQUEDA M.C., GOVINDAPPA M. Mechanisms of biocontrol and plant growth-promoting activity in soil bacterial species of Bacillus and Pseudomonas: A review. Bio-control Science and Technology. 22 (8), 855, 2012.

4. GLICK B.R. Bacteria with ACC deaminase can promote plant growth and help to feed the world. Microbiol. Res. 169 (1), 30, 2014.

5. JANKIEWICZ U. Bioactive metabolites of rhizosphere Pseudomonas bacteria. Water-Environment-Country Areas. T.10, 2 (30), 83, 2010 [In Polish].

6. WARACZEWSKA Z., NIEWIADOMSKA A., KOSICKA-DZIECHCIAREK D. The use of synergistic microorganisms in the process of nitrogen biological fixation. Woda-Środowisko-Obszary Wiejskie. 17 (2), 157, 2017 [In Polish].

7. BOROWIAK K., NIEWIADOMSKA A., SULEWSKA H., SZYMAŃSKA G., GŁUCHOWSKA K., WOLNAMARUWKA A. Effect of PRP SOL and PRP EBV nutrition on yield, photosynthesis and soil microbial activity of three cereal species. Feb-Fresenius Environ. Bull. 25, 2026, 2016.

8. TAIRO E.V., NDAKIDEMI P.A. Possible benefits of rhizobial inoculation and phosphorus supplementation on nutrition, growth and economic sustainability in grain legumes. Am. J. Res. Commun. 1 (12), 532, 2013.

9. IUSS Working Group WRB. World Reference Base for Soil Resources 2006, first update 2007. World Soil Resources Reports No.103. FAO, Rome. 2007.

10. STACHOWSKI P. Evaluation of meteorological droughts in post-mining areas in Poland in Konin area. CentralPomeranian Scientific Society for Environmental Protection. Annual Set the Environ. Protect. 12, 587, 2010.

11. SAWICKA A. The ecological aspects of dinitrogen fixation. Roczniki Akademii Rolniczej w Poznaniu.. Rozprawy Naukowe. 134, 1983 [In Polish].

12. KUNICKI-GOLDFINGER W.J.H.: Life of bacteria. PWN Warsaw, 616, 2001 [In Polish].

13. MARTIN J.P. Use of acid, rose Bengal and streptomycyn in the plate metod for estimating soil fungi. Soil Sci. 15, 215, 1950

14. OHTA A., HATTORI H. Bacteria sensitive to nutrient broth medium in terrestrial environments. Soil Sci. Plant Nutr. 26, 99, 1980.

15. GRABIŃSKA-ŁONIEWSKA. A. Laboratory exercises with general microbiology. Publishing House of Warsaw University of Technology. 1999.

16. THALMANN A. On the methodology of determination of dehydrogenase activity in soil using triphenyltetrazolium chloride (TTC). Landwirtsch. Forsh. 21, 3, 1968.

17. TABATABEI M.A., BREMNER J. Use of P-nitrophenyl phosphate for assys of soil phosphatase activity. Soil Biol. Biochem. 1, 301, 1969. 
18. JOHNSON J.I., TEMPLE K.L. Some variables affecting the measurements of catalase activity in soil Soil Sci. Soc. Am. Proc. 28, 207, 1964.

19. SAVIOZZI A., CARDELLI R., LEVI-MINZI R., RIFFALDI R. Evolution of biochemical parameters during composting of urban wastes. Comp. Sci. \& Utiliz. 12 (2), $153,2004$.

20. ABREU I., REGUERA M., BONILLA A., BOLAŇOS L., BONILLA I. Mineral Nutrition in the Legume-Rhizobia Nitrogen Fixing Symbiosis. Beneficial Plant-microbial Interactions: Ecol. Appl. 122, 2016.

21. SINGH J.S. Plant growth promoting rhizobacteria. Resonance. 18 (3), 275, 2013.

22. AHEMAD M., ZAIDI A., KHAN S., OVES M. Factors affecting the variation of microbial communities in different agro ecosystems. In: Microbial Strategies for crop improvement. Springer, Berlin Heidelberg. 301, 2009.

23. SWĘDRZYŃSKA D., SWĘDRZYŃSKI A., NIEWIADOMSKA A., STARZYK J. Efficiency of simultaneous inoculation of Italian ryegrass (Lolium multiflorum L.) seedlings with bacterial strains of Azospirillum and Rhizobium genera. Fragm. Agron. 30 (3), 172, 2013 [In Polish].

24. NIEWIADOMSKA A., SWĘDRZYŃSKA D. Effect of the Co-Inoculation of Lucerne (Medicago sativa L.) with Sinorhizobium meliloti and Herbaspirillum Frisingense in Relation to the Interactions Between Bacterial Strain, Archiv. Environ Protec. 37 (4), 25, 2011.

25. IQBAL M.I., KHALID M., SHAHZAD S.M., AHMAD M., SOLEMAN N., AKHTAR N. Integrated use of Rhizobium leguminosarum, plant growth promoting rhizobacteria and enriched compost for improving growth, nodulation and yield of Lentil (Lens culinaris Medik.) Chilean J. Agric. Res. 72 (1), 104, 2012.

26. LOPES A.R., BELLO D., PRIETO-FERNÁNDEZ Á., TRASAR-CEPEDA C., MANAIA C.M., NUNES O.C. Relationships among bulk soil physicochemical, biochemical, and microbiological parameters in an organic alfalfa-rice rotation system. Environ. Sci. Pollu. Res. 22 (15), 11690, 2015.

27. BIELIŃSKA E.J., MOCEK-PŁÓCINIAK A. Phosphatases in the soil environment. UP Pub. in Poznan, ISBN 978-837160-554-3, 2009.

28. LAISHRAM J., SAXENA K.G., MAIKHURI R.K., RAO K.S. Soil quality and soil health: A review. Int. J Ecol. Environ. Sci.. 38 (1), 19, 2012.

29. NAPORA A., GROBELAK A. Effect of sewage sludge on microbiological and biochemical activity of soil. Engin. and Environ. Prot. 17 (4), 619, 2014 [In Polish].

30. WOLIŃSKA A., STĘPNIEWSKA Z. Dehydrogenase activity in the soil environment. In: Dehydrogenases. InTech. 354, 2012.

31. BIELIŃSKA E.J., MOCEK-PŁÓCINIAK A. Impact of the tillage system on the soil enzymatic activity. Archiv. Environ. Prot. 38 (1), 75, 2012.

32. NIEWIADOMSKA A., GŁUCHOWSKA K., SWĘDRZYŃSKA D. Influence of PRP fertilization on microbial activity of soil under selected agricultural crops. Materials of the 44th National Conference on Science and Teaching " "Microorganisms in the protection of the soil environment" Poznań - Rydzyna. 70, 2010.

33. SRINIVASAN R., RAO K.J., REZA S.K., PADUA S., DINESH D., DHARUMARAJAN S. Influence of inorganic fertilizers and organic amendments on plant nutrients and soil enzyme activities under incubation. Inter. J BioResource \& Stress Manag. 7 (4), 924, 2016.
34. SWĘDRZYŃSKA D., ZIELEWICZ W., PRZYBYŁ P., STARZYK J. Effect of bio soil conditioner on microbial state and enzymatic activity of soil under Lolium perenne cultivation. Łąkarstwo w Polsce (Grassland Science in Poland). 16, 111, 2013.

35. KUMAR N., MISRA R., SHANKHDHAR S.C., SHANKDHAR D. Effect of foliar application of boron on growth, yiels, chlorophyll, amylose and nitrate reductase activity in rice. ORYZA-An International Journal on Rice. 52 (2), 123, 2015.

36. TARAN N.Y., GONCHAR O.M., LOPATKO K.G., BATSMANOVA L.M., PATYKA M.V., VOLKOGON M.V. The effect of colloidal solution of molybdenum nanoparticles on the microbial composition in rhizosphere of Cicer arietinum L. Nanoscale Res. Lett. 9 (1), 289, 2014.

37. NAHAS E. Control of acid phosphatases expression from Aspergillus niger by soil characteristics. Braz. Arch. Biol. Tech.. 58 (5), 658, 2015.

38. LEMANOWICZ J., KOPER J. Changes in the content of available phosphorus and soil phosphatase activity as a result of fertilization. Soil Science Annual. LXI (4), 140, 2010 [In Polish].

39. ROTARU V. Responses of acid phosphatase activity on the root surface and rhizospheric soil of soybean plants to phosphorus fertilization and rhizobacteria application under low water supply. Scientific Papers-Series A, Agronomy. 58, 295, 2015.

40. EREL R., BÉRARD A., CAPOWIEZ L., DOUSSAN C., ARNAL D., SOUCHE G., GAVALAND A., FRITZ C., VISSER E.J.W., SALVI S., LE MARIÉ C., HUND A., HINSINGER P. Soil type determines how root and rhizosphere traits relate to phosphorus acquisition in field-grown maize genotypes. Plant Soil. 412 (1-2), 115, 2017.

41. SWĘDRZYŃSKA D., MAŁECKA-JANKOWIAK I. The Impact of Tillaging Spring Barley on Selected Chemical, Microbiological, and Enzymatic Soil Properties. Pol. J. Environ. Stud. 26 (1), 303, 2017.

42. ROMANOWICZ A., KRZEPIŁKO A. Volumetric determination of catalase activity in various organs of the primocane-fruiting polana variety of raspberry Rubus idaeus L. and in soil it is grown on. Pol. J. Agron. 15, 49, 2013.

43. MBUTHIA L.W., ACOSTA-MARTÍNEZ V., DEBRUYN J., SCHAEFFER S., TYLER D., ODOI E., MPHESHEA M., WALKER F., EASH N. Long term tillage, cover crop, and fertilization effects on microbial community structure, activity: Implications for soil quality. Soil Biol. Bioch. 89, 24, 2015.

44. NIEWIADOMSKA A., KLAMA J., WOLNA-MARUWKA A., SULEWSKA H. Effect of manure application on the development dynamics of proteolytic and ammonification bacteria under maize (Zea mays L.) cropping. Acta Sci. Polon., Agric. 9 (1), 11, 2010.

45. ALLEN J.L., TEN-HAGE L., LEFLAIVE J. Allelopathic interactions involving benthic phototrophic microorganisms. Env. Microbiol. Rep. 8 (5), 752, 2016.

46. SWĘDRZYŃSKA D., ZIELEWICZ W., SWĘDRZYŃSKI A., STARZYK J., WOLNA-MARUWKA A. Influence of the Soleflor Soil Bioconditioner on the Microbiological State of Soil and the Vigour and Yield of Orchard Grass (Dactylis glomerata L.) Rocznik Ochrona Środowiska. 17 (2), 1320, 2015.

47. DĄBROWSKA G., ZDZIECHOWSKA E. The role of rhizobacteria in the stimulation of the growth and 
development processes and protection of plants against environmental factors. Progr. Plant Prot. 55, 498, 2015.

48. KLAMA J., NIEWIADOMSKA A., WOLNAMARUWKA A. Koinkulacja in vitro siewek kukurydzy bakteriami diazotroficznymi. Co-inoculation in vitro of maize seedlings with diazotrophic bacteria. Woda - Środowisko - Obszary Wiejskie. 10, 103, 2010 [In Polish].

49. PANDEY R.R., SHARMA G., SINGH T.B., TRIPATHI S.K. Factor influencing soil $\mathrm{CO}_{2}$ efflux in northeastern Indian oak forest and plantation. Afr. J Plant Sci. 4 (8), 280, 2010.

50. PIETRASZEK P., WALCZAK P. Characteristics and application of Bacillus strains isolated from soil. Pol. J Agron. 16, 37, 2014.

51. SADOWSKAK.,PUKACKAA., RATAJ-GURANOWSKA M. The activity of Bacillus subtilis and Pseudomonas fluorescens in vitro in inhibiting pathogenic fungal in legume plant. Progress in Plant Prot. 1 (51), 2011.

52. DIGUȚĂ C.F., MATEI F., CORNEA, C.P. Biocontrol perspectives of Aspergillus carbonarius, Botrytis cinerea and Pencillium expansum on grapes using epiphytic bacteria isolated from Romanian vineyards. Rom. Biotech. Lett. 21 (1), 11126, 2016.

53. SHAIKH S.S., SAYYED R.Z. Role of plant growthpromoting rhizobacteria and their formulation in biocontrol of plant diseases. In Plant microbes symbiosis: applied facets. Springer India. 337, 2015.

54. UTKHEDE R.S., SMITH E.M. Impact of chemical, biological and cultural treatments on the growth and yield of apple in replant-disease soil. Austral. Plant Path. 29 (2), 129, 2000.

55. MARTINEZ-VIVEROS O., JORQUERA M.A., CROWLEY D.E., GAJARDO G., MORA M.L. Mechanisms and practical considerations involved in plant growth promotion by rhizobacteria. J. Plant Nut. Soil Sc. 10 (3), 293, 2010.

56. SWĘDRZYŃSKA D., GRZEŚ S. Microbiological Parameters of Soil under Sugar Beet as a Response to the Long-Term Application of Different Tillage Systems. Pol. J Environ. Stud. 24 (1), 285, 2015. 